\title{
Advances in the endovascular treatment of direct carotid-cavernous fistulas
}

\author{
Guilherme Brasileiro de Aguiar ${ }^{1 *}$, Maurício Jory², João Miguel de Almeida Silva ${ }^{3}$, Mario Luiz Marques Conti", \\ José Carlos Esteves Veiga ${ }^{5}$

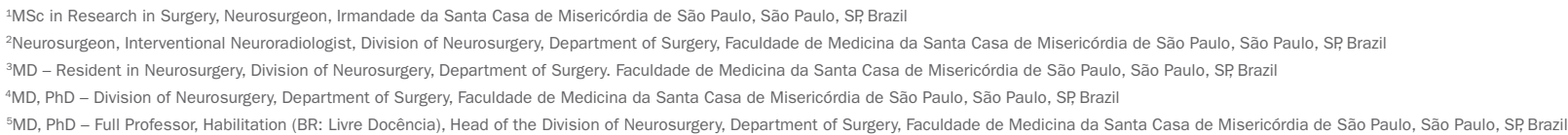

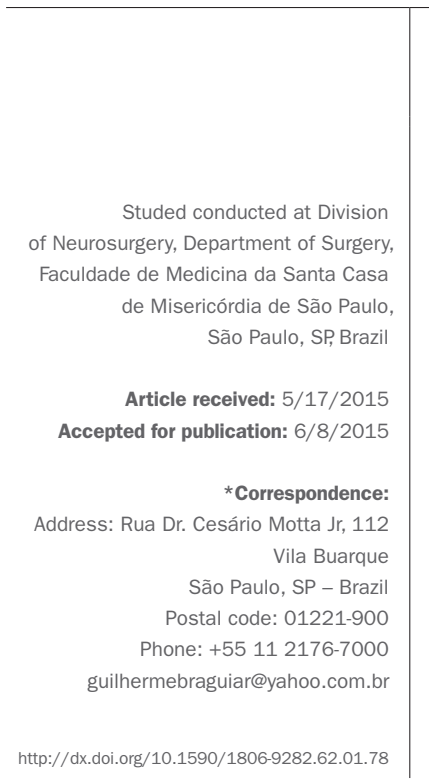

\section{SUMmarY}

Carotid cavernous fistulas (CCFs) are abnormal connections between the carotid artery and the cavernous sinus. They are considered direct when there is a direct connection between the internal carotid artery and the cavernous sinus. These cases are generally traumatic. Direct CCFs are high-flow lesions, possibly related to intracranial bleeding, visual loss, corneal exposure or even fatal epistaxis. Treatment of such lesions is, thus, always recommended. The ideal treatment for direct CCF is to exclude the fistula from circulation, preserving the carotid flow. This can be attained using diverse endovascular techniques. The objective of the present article is to review the current techniques for treatment of direct CCFs, with special attention to the currently available endovascular treatment options.

Keywords: brain injuries, carotid artery injuries, carotid-cavernous sinus fistula, endovascular procedure, endovascular treatment, therapeutic embolization.

\section{INTRODUCTION}

Carotid cavernous fistulas (CCFs) are abnormal connections between the carotid artery and the cavernous sinus (CS)..$^{1-9}$ They can be classified in several manners: according to the etiology, they can be traumatic or spontaneous, ${ }^{3,4,10}$ hemodynamically, they can represent high- or lowflow lesions; ${ }^{1,3,4,9}$ and angiographically, CCFs can be classified as direct, when the fistula originates directly in the internal carotid artery (ICA), or indirect, when the fistula originates in the dural branches of the carotid artery.,4

The angiographic classification is widely utilized, enabling prognosis and guiding the treatment plan. It also provides an objective method to group the CCFs. ${ }^{4}$ The CCFs are subdivided into four subgroups, according to the arterial supply of the fistula. Subtype A corresponds to a direct connection between the ICA and the CS, thus representing the direct CCF. Subtypes B, C and D represent indirect fistulas and are currently called dural fistulas. In subtype $\mathrm{B}$, the fistula occurs between the meningeal branches of the ICA and the CS. Subtype C is represented by the abnormal connection between meningeal branches of the external carotid artery (ECA) and the CS. In subtype $\mathrm{D}$, which is the most common, there is an abnormal connection with the CS via the arterial branches, either stemming from the ICA or the ECA. ${ }^{4}$

Thus, the direct CCF generally represents a high-flow lesion, with blood outflow from a high-pressure compartment, the ICA, to a low-pressure compartment, the CS. . $^{2,110,11}$ This generally occurs through a sole orifice in the cavernous segment of the ICA. ${ }^{4}$ In addition, direct CCFs are generally traumatic, while the indirect ones are mainly spontaneous. ${ }^{3,10,12}$ Indirect CCFs can be related to cranial venous sinus thrombosis, hormonal alterations or previous cranial surgeries. ${ }^{10}$

The great majority of the direct CCFs derive from trauma. ${ }^{3,10,13}$ Approximately a quarter of these lesions occur spontaneously, generally caused by the rupture of an intracavernous aneurysm. ${ }^{4,13}$ It is extremely important that doctors working at emergency services know how to promptly identify and diagnose this type of lesion. If it is treated rapidly, recovery from neurological deficits tends to be total. 
The treatment of these lesions has changed many times over the last few years, especially due to the introduction of new materials. The objective of the present article is to review the current techniques for treatment of direct CCFs, with special emphasis on the endovascular treatment options currently available.

\section{Methods}

A review of the literature was conducted searching the MEDLINE database using as keywords "carotid cavernous fistula". The papers that were located were analyzed, focusing mainly on those related to the treatment of direct CCFs, especially the largest published series.

The search results were presented in the format of this paper, aiming at making a comprehensive review, with emphasis on the current endovascular treatment of direct CCFs.

\section{Discussion}

\section{Epidemiology}

Direct post-traumatic CCFs are a rare condition, occurring in only $0.17-1.01 \%$ of the traumatic brain injuries (TBI). ${ }^{6,11,14,15}$ They can occur as a consequence both of closed and open TBI, the latter of which may present a direct ICA lesion. ${ }^{2,67,714,15}$ However, most direct CCFs result from a closed cranial lesion, associated with a skull base fracture. ${ }^{13,16,17}$ The direct CCFs are more common in young male patients, which is the group most commonly affected by TBI. ${ }^{4}$ Nevertheless, cranial traumas in persons of any age can result in the appearance of a direct CCF. ${ }^{4}$

The ICA is fixed between the lacerum foramen and the anterior clinoid process with dural ligaments. When a TBI occurs, the stretching forces, sometimes accompanied by penetrating bone spicules, can cause a lesion in the ICA between its fixation points. ${ }^{4}$ Most of the time, the laceration is single and unilateral. More rarely, this lesion can be multiple and bilateral. ${ }^{4,11,12}$

Despite classically being of traumatic etiology, the direct CCF can result from iatrogenic lesions, such as trans-sphenoidal or endovascular surgeries, ${ }^{4,14,15,18,19} \mathrm{col}$ lagen deficiencies, as in the Ehlers-Danlos syndrome, ruptured intracavernous aneurysms, ${ }^{4,12,13,20,21}$ dissections, osteogenesis imperfecta or even fibromuscular dysplasia. ${ }^{4}$

\section{Clinical presentation}

The clinical presentation of direct CCFs can be varied, many times being similar to the presentation of neurological diseases such as multiple sclerosis, cerebral tumors, or even encephalic vascular accidents. ${ }^{22}$

Despite the fact that direct CCFs occur as acute events, the symptoms can be insidious and potentially grave., ${ }^{4,22}$
The clinical manifestations are delayed, appearing after venous hypertension has reached a critical level, which may take weeks to happen. ${ }^{22}$ In addition, the exuberance of the clinical condition is more related to the venous drainage standard than to the size of the fistula. ${ }^{4}$ There may be compromised cranial nerves III, IV, V and VI, causing extraocular motility paralysis and diplopia, in addition to the appearance of headache, retro-ocular pain, vision loss and even intracranial hemorrhage. ${ }^{22}$ Deteriorated vision occurs due to the combination of the reduction in arterial perfusion and venous hypertension, accompanied by glaucoma and the worsening of the retina perfusion. ${ }^{1,4} \mathrm{~A}$ condition of cerebral ischemia, related to the phenomenon of "vascular theft", seems to be exceptionally rare and occurs only in patients with variations in the Willis polygon. ${ }^{4}$ There are also reports of subarachnoid hemorrhage caused by direct CCF. ${ }^{23}$ This aspect is related to the transmission of venous hypertension to the cortical veins adjacent to the lesion.

A direct CCF is formed by the blood overflow from the ICA to the CS. In this manner, there is a blood flow from a compartment of high pressure to a compartment of low pressure. This abnormal communication leads to increase in pressure in the CS and consequent compression of its contents, including the cranial nerves III, IV, V and VI. ${ }^{3-5,24}$ The involvement of these nerves results in ophthalmoplegia, alterations in face sensitivity, ptosis and photophobia. ${ }^{4,24}$ In addition, the occurrence of ophthalmoplegia is facilitated by edema in intraorbital and periocular structures ${ }^{4}$ (Figure 1). Venous hypertension leads to engorgement of the ophthalmic veins, causing the classic triad of direct CCF: ocular bruit, chemosis and pulsatile exophthalmos. ${ }^{1,4,24}$ In addition, the intracavernous pressure can be transmitted to the contralateral CS through the intercavernous sinuses, resulting in bilateral ocular deficits. ${ }^{4,22}$

The symptoms usually improve significantly following treatment, many times achieving resolution in hours or days. Total recovery, however, can take weeks or months. ${ }^{4}$ Thus, the duration of the symptoms seems to be an important prognostic factor, being that those patients with prolonged symptomatology take longer to achieve a satisfactory recuperation. ${ }^{4}$

\section{Diagnosis}

The diagnosis of direct CCF is based on its clinical presentation, as well as on neuroimaging exams. ${ }^{22}$ Computerized tomography (CT) of the skull without contrast can show ocular proptosis, engorgement and tortuosity of the superior ophthalmic vein, as well as the enlargement 


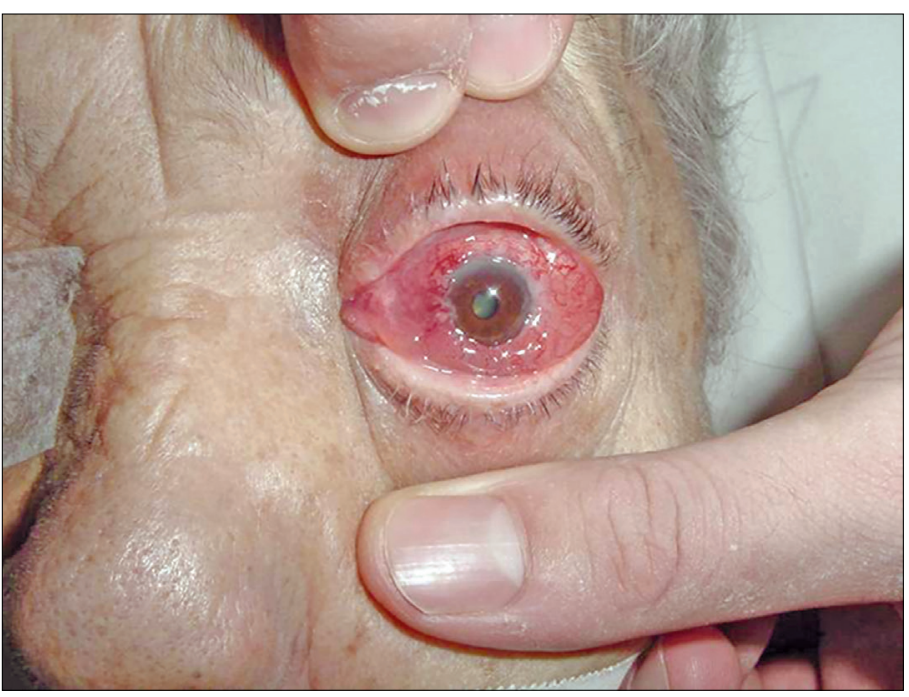

FIGURE 1 Photograph of a patient with a direct carotid-ca vernous fistula, demonstrating intense conjunctival edema and ocular hyperemia.

Thus, by definition, every direct CCF must be readi-

of the CS involved. ${ }^{22}$ Magnetic resonance imaging (MRI) of the brain shows similar findings to those of the CT, but with better definition, being also particularly useful in the classification of the CCFs. ${ }^{22} \mathrm{CT}$ and MRI are also important in evaluating the encephalic parenchyma, for the identification of possible traumatic lesions or even associated ischemia. ${ }^{4}$ In addition, CT in coronal view is widely used in the evaluation of possible bone lesions at the skull base. ${ }^{4}$

The best exam for the diagnosis and classification of the CCFs is cerebral angiography (Figure 2). ${ }^{4,7}$ It is performed with the objective of identifying location and size of the fistula, as well as its venous drainage. ${ }^{4}$ In addition, by this method it is possible to identify associated vascular lesions, such as pseudoaneurysms or varicose veins in the CS, which also require treatment. ${ }^{4}$ As this is a high-flow lesion, it is often difficult to visualize the morphology of the fistula orifice. To obtain a more detailed image, the Allcock maneuver can be utilized, which consists of ICA compression ipsilateral to the fistula, with the injection of a contrast in the vertebral artery or even in the contralateral ICA (Figure 3). ${ }^{4}$

\section{Treatment}

Direct CCFs are high-flow lesions that can be related to intracranial bleeding, visual loss, corneal exposure or even fatal epistaxis ${ }^{4,22}$ and, therefore, their treatment is always recommended. Treatment must be provided as soon as possible, and to reinforce this, Halbach et al. ${ }^{25}$ identified some high-risk situations, which require urgent treatment. These include the onset of intracranial hemorrhage, epistaxis, increase in the intraocular pressure, reduction of visual acuity and rapidly progressive proptosis. ly treated. In the past, before the development of endovascular techniques, the treatment of this type of lesion was to perform the ligature or trapping of the ICA, often with severe sequelae and persistence of fistula. ${ }^{2,4,26}$ Currently, endovascular treatment is the procedure of choice for these lesions. ${ }^{2,4,5,8,9}$ Once the lesion is treated, the CS pressure is normalized, allowing symptoms to subside. ${ }^{22}$ Drug treatment must be promptly instituted in the form of local care provided to the eyes for as long as it takes to reverse the clinical condition. ${ }^{4}$ Some authors affirm that there should be a one- to two-week delay following the onset of the symptoms to perform the endovascular treatment. ${ }^{12}$ They state that, due to the recent cranial trauma, the ICA could present a strong reaction to the endovascular navigation, which would cause greater risk of endothelial lesion. ${ }^{12}$ However, some cases need treatment in the acute phase, generally due to the imminent risk of intracranial hemorrhage, caused by venous hypertension, ${ }^{12}$ or to the rapid deterioration of the vision. ${ }^{22}$

The ideal treatment for a direct CCF is the exclusion of the fistula from the circulation, preserving the patency of the ICA. ${ }^{4,6,9,12,14,15}$ From the 1970 s on, this began to be successfully achieved using detachable balloons. ${ }^{4,11,27}$ Currently, a variety of new materials and different strategies have been used in the treatment of direct CCFs. ${ }^{4,11}$ In this manner, direct CCFs can be managed successfully both via artery or vein, or even transorbitally (through the superior ophthalmic vein). ${ }^{4}$

The gold standard for treatment is the transarterial route, with occlusion of the fistula and preservation of the blood flow through the ICA. This is achieved with the positioning of a latex balloon in the CS, occluding the fistula orifice. , $6,8,14,15,20,28$ Nevertheless, in some countries, 

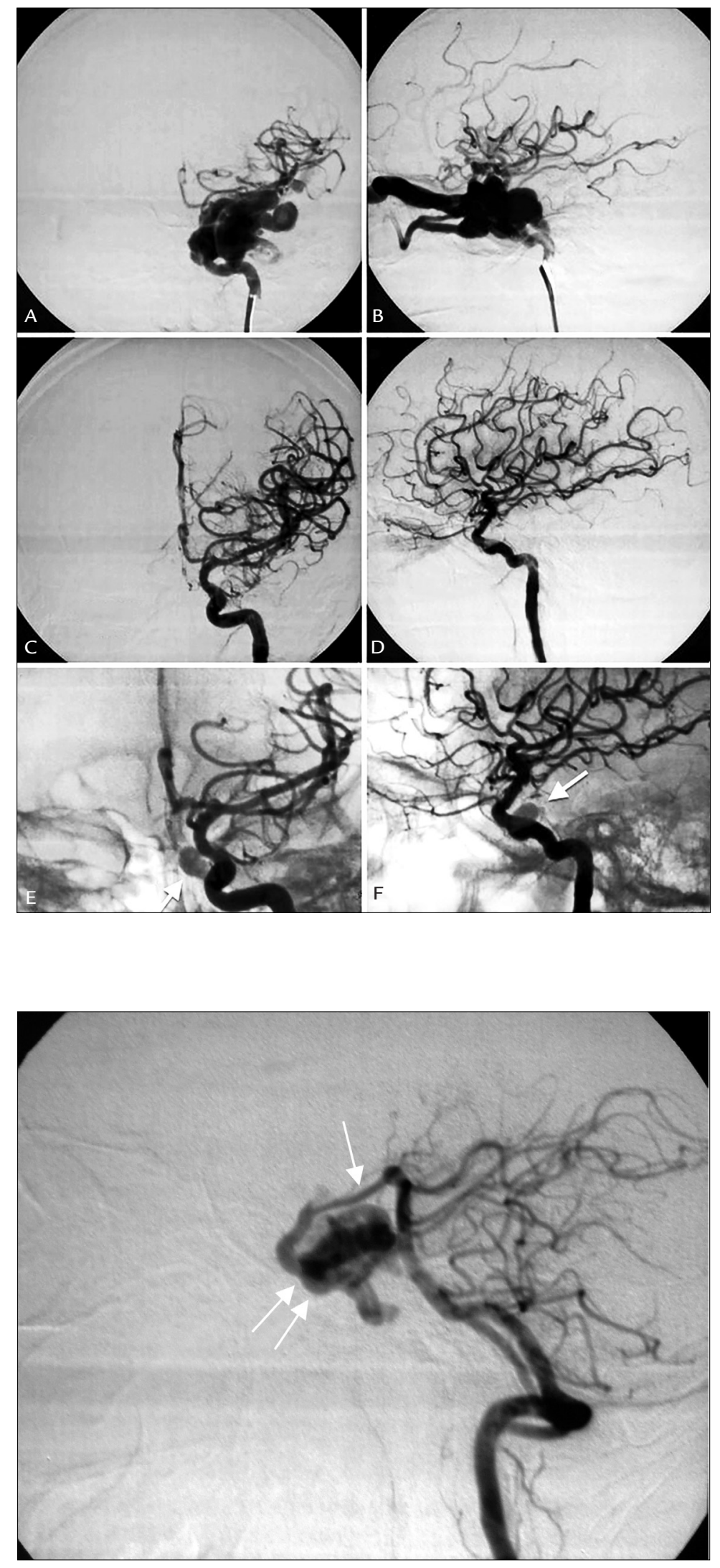

FIGURE 2 Left carotid angiography before (A and B) and after (C-F) endovascular treatment of the direct CCF. $A$ and $B$ : early opacification of the left cavernous sinus, with cerebral blood flow deviation; C and D: normal opacification of the left cerebral hemisphere; $\mathrm{E}$ and $\mathrm{F}$ : carotid angiography showing the positioning of the balloon (arrow) in the left cavernous sinus (A-C-E: frontal incidence; B-D-F: lateral incidence).
FIGURE 3 Left vertebral angiography, with left carotid compression, demonstrating the opacification of the left CCF (double arrow) by means of the flow inversion in the posterior communicating artery (arrow) in the Allcock maneuver. 
such as the United States, detachable balloons are not used, ${ }^{11}$ making another type of approach necessary. In addition, the failure rate for selective occlusion of the fistula with a balloon is as high as $10 \%{ }^{4,29-31}$ Frequently, the failure of this technique occurs because of the small size of the fistula orifice, making it impossible for the balloon to pass through, or even the small size of the CS, which makes it impossible to adequately inflate the balloon. ${ }^{4}$ The navigation of the microcatheter to reach the fistula may also be a limiting factor in this option, especially if the fistula is located in the segment $\mathrm{C} 4$ of the cavernous ICA, due to a very acute entrance angle to the ICA. ${ }^{4}$ The presence of bone spicules may lead to perforation of the balloon during inflation, ${ }^{32}$ which also constitutes a limitation to this technique.

Another negative aspect of occluding the fistula with a balloon technique is the appearance of thromboembolic complications related to the procedure, generally caused by the manipulation of the balloon, with an adjacent endothelial lesion. ${ }^{4}$ In patients with complex CCFs, it has been observed that associated with this technique is the presence of residual CCFs, or even recurrent ones, as well as the formation of pseudoaneurysms. This aspect is associated with an incomplete occlusion of the orifice. $^{14,15}$

Although not so widely known, there is also the possibility of selective occlusion of the CS, preserving the patency of the ICA, using detachable platinum coils, which are released in a controlled manner into the interior of the CS..$^{4,11,33}$ This technique can be enhanced by the use of adhesive liquids (cyanoacrylates) or Onyx $x^{\circledR}$, in an attempt to obtain occlusion of the fistula., ${ }^{4}, 3$ Despite having greater chances for success with this association, it must be remembered that there is a possibility of liquid agent reflux into the ICA, with consequent distal embolization of the carotid territory and possible ischemic sequelae. $^{4}$

Even though the treatment's objective is to preserve the ICA flow, $, 12,14,15$ this is not always possible. In situations in which it is not possible to achieve selective occlusion of the fistula, either with a balloon or with detachable platinum coils, there is the option of definitive occlusion of the ICA to close the fistula, ${ }^{4,11}$ performed through the transarterial route as well. In this manner, when it is performed with balloons, these should be positioned so as to occlude the fistula orifice, interrupting its flow. ${ }^{4,11}$ When it is performed with platinum coils, these should be released into the CS, but also occluding the ICA, so as to prevent its distal migration and to guarantee the occlusion of the ICA.
As the ICA flow is almost exclusively directed to the fistula, it is not necessary to perform the ICA occlusion test before sacrificing it. ${ }^{4}$ Nevertheless, in patients who present with good opacification in the cerebral parenchyma distal to the fistula, the ICA occlusion test is recommended before proceeding with the therapeutic occlusion of this artery. If the patient does not tolerate the occlusion, another method of treatment should be adopted, ${ }^{4}$ such as vascular bypass, for example.

Although the standard treatment for a direct CCF is most frequently performed via the artery, by means of selective occlusion of the fistula and preservation of the ICA patency with a balloon, the embolization of the affected CS using platinum coils and accessing the region by the transvenous route has been used currently, mainly due to safety of its execution and the high rate of success obtained. ${ }^{12,28,33}$

Access through the ipsilateral jugular vein and inferior petrosal sinus (IPS) is the venous route most often used for access to the affected CS. ${ }^{4,8,12,35}$ After positioning the microcatheter in this CS, the occlusion of the sinus, and consequently of the fistula, can be performed using a detachable balloon, detachable coils, tissue adhesives or Onyx ${ }^{\circledR}$, or even a combination of these. ${ }^{4,36}$ During the procedure, a catheter should be positioned in the ICA for injection of contrast at this site and subsequent pinpointing of the fistula and the CS, as well as to confirm the occlusion of the fistula. In cases in which it is impossible to use the ipsilateral IPS, other venous routes can be used, such as the contralateral IPS, the pterygoid plexus veins, the superior ophthalmic vein and even the cortical veins through the sphenoparietal sinus. ${ }^{4}$

This transvenous route, although anatomically favorable, is not exempt from complications. ${ }^{4,12}$ Protrusion of coils to the ICA can occur, especially in large fistulas, ${ }^{12}$ but this complication can be minimized by using a balloon for protection, positioned in the ICA during the release of the coils. There is the possibility of subarachnoid hemorrhage, especially by lesions in the petrosal sinuses or cortical veins during the manipulation of the catheters, ${ }^{4,12}$ also due to the hemodynamic alteration caused by the change in the venous drainage pattern which occurs with the use of embolic agents. ${ }^{4}$ There is a risk of transitory paralysis in the oculomotor and abducent nerves due to the compressive effect caused in the CS. ${ }^{12}$

Another possibility of access to the compromised CS is through the orbit, by means of direct puncturing of the superior ophthalmic vein. ${ }^{4}$ In CCF cases, this vein is generally congested, facilitating the access to that compartment for the occlusion of the lesion. 
The most recent advance in the endovascular treatment of direct CCFs is the utilization of covered stents, which provide the occlusion of the fistula and preservation of the ICA flow. ${ }^{411,14,15,37}$ This transarterial technique not only preserves the ICA, but also remodels it, and aims to simplify the endovascular procedure, reducing both procedure time and the costs involved in the treatment of CCFs. ${ }^{14,15}$ An expandable polytetrafluoroethylene (PTFE - teflon) prosthesis is used, making it possible to obtain a higher rate of complete fistula occlusion, as well as to reduce the incidence of recurrences and the forming of pseudoaneurysms, with the objective of completely covering the fistula orifice. ${ }^{14,15,37}$ There are also reports on the successful use of flow diverter stents in the treatment of the traumatic CCF. ${ }^{38}$

When comparing traditional embolization with coils techniques, Wang et al. ${ }^{14}$ pointed out some advantages in the utilization of the covered stent over the latter: the positioning of the stent is a simple and rapid procedure; it does not have the risk of herniation or coil migration; it promotes the disappearance of the mass effect and local compression, and it is not accompanied by the formation of pseudoaneurysms. Also according to the same authors, the use of stents in the management of direct CCFs, instead of using coils or balloons, provides a substantial increase in the fistula occlusion rate and anatomical cure, eliminating the possibilities of recanalization and reducing the costs of eventual retreatment for recurrent lesions. For Yin et al. ${ }^{39}$ in a non-randomized prospective study published in 2012, the angiographic and clinical results obtained with the utilization of covered stents are superior to those obtained with the use of detachable balloons.

However, there are some disadvantages in using these stents to treat CCFs. ${ }^{4,11,14,15}$ There is a risk of late stent thrombosis, but this can be minimized by instituting the correct anticoagulant / antiplatelet therapy. ${ }^{4,11,14,15,37}$ The disadvantage is that this therapy cannot be used in patients in the acute phase of the trauma. Difficulty in navigation and the release of stents into small-caliber and generally tortuous vessels is the major limitation to this technique, but which has been increasingly overcome with the use of new materials that were specially developed for intracranial vessels. ${ }^{11}$

Cho et al. ${ }^{11}$ report the occurrence of cerebral hemorrhage following the utilization of a covered stent. This aspect can stem from the reperfusion mechanism. The theory of reperfusion was described by Spetzler as a possible cause of intracranial hemorrhage, following the resection of cerebral arteriovenous malformations, due to the loss of self-regulation, with an increase in the local flow associated with edema in the adjacent structures. ${ }^{11}$ Numerous accounts have associated the theory of reperfusion with the onset of intracranial hemorrhages following diverse revascularization techniques, including carotid endarterectomies and bypass. There are other factors involved in the genesis of this phenomenon, such as the possible release of free radicals, with endothelial lesion, or local sympathetic response. ${ }^{11}$

\section{Conclusion}

Direct CCF constitutes a rare disease, occurring generally after a closed TBI. Its treatment involves the utilization of diverse endovascular techniques, usually successful in the outcome. The use of a detachable balloon, with fistula occlusion and ICA flow preservation, still represents the most widely accepted treatment for this condition. However, the use of covered stents arose as a viable alternative, which makes the treatment of the great majority of the cases of direct CCF possible, especially in young patients who have favorable vascular anatomies. Nevertheless, new studies and a longer follow-up of these patients are necessary in order to come to definitive conclusions.

\section{Resumo}

Avanços no tratamento endovascular de fístulas carotidocavernosas diretas

As fístulas carotidocavernosas (FCC) são comunicações anormais entre a artéria carótida e o seio cavernoso. Elas são consideradas diretas quando há uma comunicação direta entre a artéria carótida interna e o seio cavernoso. Nesses casos, são geralmente traumáticas. As FCC diretas são lesões de alto fluxo, podendo estar relacionadas a sangramento intracraniano, perda visual, exposição corneana ou até mesmo a epistaxe fatal. Seu tratamento é sempre indicado. O tratamento ideal da FCC direta é a exclusão da fístula da circulação, com preservação do fluxo carotídeo. Isso pode ser obtido por meio de técnicas endovasculares diversas. O objetivo do presente artigo é realizar uma revisão sobre as FCC diretas, com especial enfoque nas opções de tratamento endovascular disponíveis na atualidade.

Palavras-chave: traumatismo craniocerebral, lesões das artérias carótidas, fístula carotidocavernosa, procedimentos endovasculares, embolização terapêutica. 


\section{References}

1. Grumann AJ, Boivin-Faure L, Chapot R, Adenis JP, Robert PY. Ophthalmologic outcome of direct and indirect carotid cavernous fistulas. Int Ophthalmol 2012; 32(2):153-9

2. Ellis JA, Goldstein H, Connolly ES Jr, Meyers PM. Carotid-cavernous fistulas. Neurosurg Focus. 2012; 32(5):E9.

3. Kim JW, Kim SJ, Kim MR. Traumatic carotid-cavernous sinus fistula accompanying abducens nerve (VI) palsy in blowout fractures: missed diagnosis of 'white-eyed shunt'. Int J Oral Maxillofac Surg. 2013; pii:S09015027(13)00026-X

4. Kanamalla US, Jungreis CA, Kochan JP. Direct carotid cavernous fistula. In: Hurst RW, Rosenwasser RH (eds.). Interventional neuroradiology. 1.ed. New York: Informa Healthcare USA, 2008. p.231-8.

5. Ducruet AF, Albuquerque FC, Crowley RW, McDougall CG. The evolution of endovascular treatment of carotid cavernous fistulas: a single-center experience. World Neurosurg. 2013; pii:S1878-8750(13)00298-2.

6. Malan J, Lefeuvre D, Mngomezulu V, Taylor A. Angioarchitecture and treatment modalities in posttraumatic carotid cavernous fistulae. Interv Neuroradiol. 2012; 18(2):178-86.

7. Aissa A, Arous A, Alouini R, Taktak J, Allani M. [Ballistic trauma resulting in carotid-cavernous fistula]. J Fr Ophtalmol. 2012; 35(9):722.

8. Pang PF, Jiang ZB, Zhou B, Li ZR, Huang MS, Zhu KS, et al. [Diagnosis and treatment of carotid-cavernous fistula: analysis of 28 patients]. Zhonghua Yi Xue Za Zhi. 2012; 92(21):1458-62.

9. Gemmete JJ, Ansari SA, Gandhi DM. Endovascular techniques for treatment of carotid-cavernous fistula. J Neuroophthalmol. 2009; 29(1):62-71.

10. Uehara T, Tabuchi M, Kawaguchi T, Mori E. Spontaneous dural carotid cavernous sinus fistula presenting isolated ophthalmoplegia: evaluation with MR angiography. Neurology. 1998; 50:814-6.

11. Cho KC, Seo DH, Choe IS, Park SC. Cerebral hemorrhage after endovascular treatment of bilateral traumatic carotid cavernous fistulae with covered stents. J Korean Neurosurg Soc. 2011; 50:126-9.

12. Mercado GB, Irie K, Negoro M, Moriya S, Tanaka T, Ohmura M, et al. Transvenous embolization in spontaneous direct carotid-cavernous fistula in childhood. Asian J Neurosurg. 2011; 6(1):45-8.

13. Barrow DL, Spector RH, Braun IF. Classification and treatment of spontaneous carotid cavernous sinus fistulas. J Neurosurg. 1985; 62:248-56.

14. Wang YL, Ma J, Ding PX, Li YD, Han XW, Wu G. Treatment of post-traumatic carotid-cavernous fistulas with the Willis covered stent. A preliminary prospective study. Interv Neuroradiol. 2012; 18(2):172-7.

15. Wang YL, Ma J, Li YD, Ding PX, Han XW, Wu G. Application of the Willis covered stent for the management of posttraumatic carotid-cavernous fistulas: an initial clinical study. Neurol India. 2012; 60(2):180-4.

16. Newton TH, Hoyt WF. Dural arteriovenous shunts in the region of the cavernous sinus. Neuroradiology. 1970; 1:71-81.

17. Debrun GM, Vinuela F, Fox AJ, Davis KR, Ahn HS. Indications for treatment and classification of 132 carotid-cavernous fistulas. Neurosurgery. 1988; 22(2):285-9.

18. Kwon HJ, Jin SC. Spontaneous healing of iatrogenic direct carotid cavernous fistula. Interv Neuroradiol. 2012; 18(2):187-90.

19. Conti MLM, Aguiar GB, Veiga JCE, Santos ARL, Lazarini PR, Jory M, et al. Endovascular treatment of iatrogenic pseudoaneurysm and delayed carotidcavernous fistula following transsphenoidal surgery. Rev Chil Neurocirugía. 2012; 38(2):147-50.

20. Wang Q, Chen G. Endovascular treatment of bilateral multiple carotidcavernous fistulas in a patient with Ehlers-Danlos syndrome. J Neurol Surg A - Cent Eur Neurosurg. 2013; 74 Suppl 1:e41-4.
21. Doğan S, Salman MC, Deren O, Geyik S. Carotid-cavernous fistula in term pregnancy due to spontaneous rupture of carotid-cavernous aneurysm. Obstet Gynaecol Res. 2012; 38(2):427-30

22. Kaplan JB, Bodhit AN, Falgiani ML. Communicating carotid-cavernous sinus fistula following minor head trauma. Intl J Emerg Med. 2012; 5:10.

23. Asano T, Houkin K, Moriwaki T, Niiya Y, Mabuchi S. [Case of direct carotidcavernous fistula presenting with subarachnoid hemorrhage]. No Shinkei Geka. 2012; 40(3):235-9.

24. Kocer N, Kizilkilie O, Albayram S, Adaletli I, Kantarci F, Islak C. Treatment of iatrogenic internal carotid artery laceration and carotid cavernous fistula with endovascular stent-graft placement. AJNR Am J Neuroradiol. 2002; 23(3):442-6.

25. Halbach VV, Hieshima GB, Higashida RT, Reicher M. Carotidcavernous fistulae: indications for urgent therapy. AJR Am J Roentgenol. 1987; 149(3):587-93.

26. Sanders MD, Hoyt WF. Hypoxic ocular sequelae of carotid-cavernous fistulae. Study of the causes of visual failure before and after neurosurgical treatment in a series of 25 cases. Br J Ophthalmol. 1969; 53:82-97.

27. Lewis A, Tomsick TA, Tew JJ. Management of 100 consecutive direct carotidcavernous fistulas: results of treatment with detachable balloons. Neurosurgery. 1995; 36:239-44.

28. Gonzalez LF, Chalouhi N, Tjoumakaris S, Jabbour P, Dumont AS Rosenwasser RH. Treatment of carotid-cavernous fistulas using intraarterial balloon assistance: case series and technical note. Neurosurg Focus. 2012; 32(5):E14.

29. Halbach VV, Higashida RT, Barnwell SL, Dowd CF, Hieshima GB Transarterial platinum coil embolization of carotid-cavernous fistula. AJNR Am J Neuroradiol. 1991; 12(3):429-33.

30. Halbach VV, Higashida RT, Hieshima GB, Hardin CW, Yang PJ. Transvenous embolization of direct carotid cavernous fistulas. AJNR Am J Neuroradiol. 1988; 9(4):741-7.

31. Moron FE, Klucznik RP, Mawad ME, Strother CM. Endovascular treatment of high-flow carotid cavernous fistulas by stentassisted coil placement. AJNR Am J Neuroradiol. 2005; 26(6):1399-404.

32. Horton JA, Jungreis CA, Stratemeier PH. Sharp vascular calcifications and acute balloon rupture during embolization. AJNR Am J Neuroradiol. 1991; 12:1070-3.

33. Luo CB, Teng MM, Chang FC, Lin CJ, Guo WY, Chang CY. Transarterial detachable coil embolization of direct carotid-cavernous fistula: immediate and long-term outcomes. J Chin Med Assoc. 2013; 76(1):31-6.

34. Yu Y, Huang Q, Xu Y, Hong B, Zhao W, Deng B, et al. Use of onyx for transarterial balloon-assisted embolization of traumatic carotid cavernous fistulas: a report of 23 cases. AJNR Am J Neuroradiol. 2012; 33(7):1305-9.

35. Bing F, Albrieux M, Vinh Moreau-Gaudry V, Vasdev A. Cavernous sinus fistula treated through the transvenous approach: report of four cases. J Neuroradiol. 2009; 157:1-5.

36. Zenteno M, Santos-Franco J, Rodríguez-Parra V, Balderrama J, AburtoMurrieta Y, Vega-Montesinos S, et al. Management of direct carotid-cavernous sinus fistulas with the use of ethylene-vinyl alcohol (Onyx) only: preliminary results. J Neurosurg. 2010; 112(3):595-02.

37. Kalyanpur TM, Narsinghpura K, Yadav M, Mehta P, Paul K, Cherian M. Covered coronary stent grafts as a treatment option for carotid-cavernous fistulas: our initial experience. Neurol India. 2011; 59(6):895-8.

38. Nadarajah M, Power M, Barry B, Wenderoth J. Treatment of a traumatic carotid-cavernous fistula by the sole use of a flow diverting stent. J Neurointery Surg. 2012; 4(3):e1

39. Yin B, Sheng HS, Wei RL, Lin J, Zhou H, Zhang N. Comparison of covered stents with detachable balloons for treatment of posttraumatic carotidcavernous fistulas. J Clin Neurosci. 2013; 20(3):367-2. 